Article

\title{
Antibacterial Potential of Extracts and Phytoconstituents Isolated from Syncarpia hillii Leaves In Vitro
}

\author{
Muthukuttige M. N. Perera (D), Satish N. Dighe *, Peter L. Katavic and Trudi A. Collet*(D) \\ Innovative Medicines Group, Faculty of Health, Queensland University of Technology, 60 Musk Avenue, \\ Kelvin Grove, QLD 4059, Australia; muthukuttige.perera@hdr.qut.edu.au (M.M.N.P.); \\ pakatavic@gmail.com (P.L.K.) \\ * Correspondence: sdighe2008@gmail.com (S.N.D.); t.collet@qut.edu.au (T.A.C.)
}

Citation: Perera, M.M.N.; Dighe, S.N.; Katavic, P.L.; Collet, T.A. Antibacterial Potential of Extracts and Phytoconstituents Isolated from Syncarpia hillii Leaves In Vitro. Plants 2022, 11, 283. https://doi.org/ $10.3390 /$ plants 11030283

Academic Editors: RodicaMihaela Dinicǎ and Bianca Furdui

Received: 22 December 2021

Accepted: 13 January 2022

Published: 21 January 2022

Publisher's Note: MDPI stays neutral with regard to jurisdictional claims in published maps and institutional affiliations.

Copyright: (C) 2022 by the authors. Licensee MDPI, Basel, Switzerland. This article is an open access article distributed under the terms and conditions of the Creative Commons Attribution (CC BY) license (https:// creativecommons.org/licenses/by/ $4.0 /)$.

\begin{abstract}
Background: Rapidly increasing antibiotic resistance is one of the greatest threats to global health, affecting individuals regardless of age. Medicinal plants are widely used in traditional medicine to prevent and attenuate infectious conditions with minimal adverse effects. However, only a few have been phytochemically investigated for their medicinal properties and subsequent biological activities. Syncarpia hillii, a plant traditionally used by Indigenous Australians to treat sores, wounds, and skin infections, is no exception. (2) Methods: Primary extracts obtained from mature $S$. hillii leaves were evaluated for their antibacterial potential against 19 bacterial strains. The methanol extract was subjected to compound isolation and identification due to its preliminary bactericidal efficacy. (3) Results: Staphylococcal species were the most susceptible bacterial strain with a MIC value of $0.63 \mathrm{mg} / \mathrm{mL}$ to the $S$. hillii methanol extract. Quercetin-3-O- $\beta$-D-glucuronide and shikimic acid isolated from $S$. hillii methanol leaf extracts exhibited enhanced antibacterial effects against the tested bacteria with quercetin-3-O- $\beta$-D-glucuronide eliciting a MIC value of $0.78 \mu \mathrm{g} / \mathrm{mL}$ against E. faecalis. (4) Conclusions: S. hillii leaves are comprised of bioactive compounds that are bactericidal against several Gram-positive and Gram-negative bacteria.
\end{abstract}

Keywords: extract; phytochemicals; Syncarpia hillii; antimicrobial

\section{Introduction}

Plants are a well-known source of active metabolites and, hence, form the basis of numerous pharmaceutical products [1,2]. At present, $80 \%$ of the world's population uses medicinal plants to treat basic illnesses, mostly as extracts or isolated active compounds [3].

Indigenous Australians are known for using a diverse range of plant species for the treatment of different ailments; however, only a few have been investigated for their medicinal properties [4]. Syncarpia hillii, a plant used in Australian traditional medicine [5] that grows primarily in southeast Queensland and, more predominantly, Fraser Island [6,7], has been shown to contain very different essential oils from other species of the same genus [8]. Using steam distillation and other analytical techniques, the oil was found to be comprised of 53-80\% hillyl acetate, $6-12 \%$ hillone [9], 22\% $\alpha$-pinene, a smaller quantity of monoterpenes such as $\alpha$-thujene, $p$-cymene, and terpinen-4-ol, and several sesquiterpenes [9]. Nevertheless, apart from traditional knowledge of Indigenous Australian communities regarding the use of $S$. hillii for treating wounds and skin-related infections [5], only a minimal number of studies pertaining to the pharmacological effects of the plant have been undertaken $[7,9,10]$.

Multi-drug-resistant microorganisms and their associated biofilms have become a global challenge [11], as the majority of antibiotics currently in use were discovered prior to 1970 [12]. Therefore, the discovery and development of new antimicrobial drugs with novel modes of action are essential to control the emergence of multi-drug-resistant pathogens [13]. 
As such, the aim of this current study was to evaluate the antimicrobial potential of primary extracts obtained from $S$. hillii leaves against 19 Gram-positive and Gram-negative bacteria and subsequently isolate and identify the bioactive phytochemicals responsible for the bactericidal effect. The methanol extract was further tested for biofilm eradication activity due to its superior antibacterial potential compared to other primary extracts against methicillin-resistant Staphylococcus aureus (MRSA). Upon phytochemical analysis, two compounds were isolated from the $S$. hillii primary methanol extract and also evaluated for their antimicrobial activity. Overall, this is the first study to report the detailed extraction, isolation, and bactericidal efficacy of leaf-derived extracts and compounds from S. hillii.

\section{Results}

\subsection{Antibacterial Effects of Primary Methanolic Extracts}

Aqueous, methanol, ethanol, isopropanol, and hexane extracts obtained from $S$. hillii mature leaves at a concentration of $100 \mathrm{mg} / \mathrm{mL}$ were tested against 19 bacterial strains using the WDA (Table 1). Comparatively, the ethanol and methanol extracts demonstrated the highest level of inhibition and were shown to be bactericidal against all Gram-positive and four Gram-negative bacteria. However, the inhibitory effect of both extracts did not exceed the ZOI elicited by the standard antibiotic control for any of the bacteria tested. The inhibitory effect of both the methanol and ethanol extracts were almost identical, although the methanol fraction was marginally superior with regard to antimicrobial activity against Gram-negative bacteria, i.e., P. vulgaris, P. mirabilis, and A. baumannii. Moreover, the ZOI produced by aqueous $(6.56 \pm 0.83)$ and methanol $(6.33 \pm 0.45, p<0.0001)$ extracts against the clinical isolate of MRSA (ATCC 33591) was only slightly less compared to the antibiotic control $(7.00 \pm 0.00)$. In general, a higher antimicrobial activity was demonstrated in those fractions extracted with polar solvents compared to nonpolar solvents.

Table 1. Antibacterial effects of $S$. hillii primary leaf extracts.

\begin{tabular}{|c|c|c|c|c|c|c|}
\hline \multirow[t]{2}{*}{ Bacterial Strain } & \multirow{2}{*}{$\begin{array}{c}\text { Antibiotic } \\
\text { Standard ZOI } \\
(\mathrm{mm})\end{array}$} & \multicolumn{5}{|c|}{$\begin{array}{l}\text { Average ZOI (mm) for S. hillii Extracts } \\
\qquad(100 \mathrm{mg} / \mathrm{mL})\end{array}$} \\
\hline & & Aqueous & Methanol & Ethanol & Isopropanol & Hexane \\
\hline \multicolumn{7}{|l|}{ Gram-positive bacteria } \\
\hline Bacillus cereus (ATCC 14579) & $7.00 \pm 0.00$ & $3.56 \pm 0.50$ & $5.00 \pm 0.00$ & $5.28 \pm 0.42$ & $3.22 \pm 0.63$ & $1.56 \pm 0.68$ \\
\hline MSSA (NCTC 6571) & $11.33 \pm 1.89$ & $4.44 \pm 0.50$ & $5.89 \pm 0.54$ & $6.00 \pm 0.82$ & $4.22 \pm 0.63$ & $3.89 \pm 0.74$ \\
\hline MRSA (QUT 1113) & $8.33 \pm 0.24$ & $6.44 \pm 0.50$ & $7.33 \pm 0.45$ & $6.67 \pm 0.47$ & $5.78 \pm 0.92$ & $3.56 \pm 0.50$ \\
\hline MRSA (ATCC 33591) & $7.00 \pm 0.00$ & $6.56 \pm 0.83$ & $6.33 \pm 0.45$ & $5.89 \pm 0.57$ & $5.78 \pm 0.92$ & $2.89 \pm 0.87$ \\
\hline Bacillus subtilis (QUT 0535) & $9.00 \pm 0.00$ & NA & $4.33 \pm 0.45$ & $4.00 \pm 0.00$ & $1.89 \pm 0.57$ & $1.67 \pm 0.47$ \\
\hline Staphylococcus epidermidis (QUT 0613) & $9.00 \pm 0.00$ & $3.67 \pm 0.47$ & $5.67 \pm 0.45$ & $5.17 \pm 0.33$ & $2.67 \pm 0.67$ & $0.56 \pm 0.50$ \\
\hline Enterococcus faecalis (QUT code 1105) & $3.00 \pm 0.00$ & NA & $2.33 \pm 0.45$ & $2.33 \pm 0.47$ & NA & $1.89 \pm 0.31$ \\
\hline Enterococcus faecium (QUT code 1101) & $6.00 \pm 0.00$ & NA & $2.33 \pm 0.45$ & $2.78 \pm 0.42$ & $2.00 \pm 0.82$ & $2.33 \pm 0.47$ \\
\hline Enterococcus gallinarum (ATCC 49573) & $4.00 \pm 0.00$ & $0.89 \pm 0.74$ & $1.33 \pm 0.45$ & $2.67 \pm 0.67$ & NA & $2.67 \pm 0.47$ \\
\hline Enterococcus casseliflavus (ATCC 25788) & $4.00 \pm 0.00$ & NA & $2.00 \pm 0.00$ & $2.00 \pm 0.67$ & NA & $0.67 \pm 0.47$ \\
\hline Staphylococcus saprophyticus (QUT 0703) & $8.00 \pm 0.00$ & $4.22 \pm 0.42$ & $5.00 \pm 0.00$ & $4.78 \pm 0.42$ & $3.78 \pm 0.42$ & $2.22 \pm 0.42$ \\
\hline \multicolumn{7}{|l|}{ Gram-negative bacteria } \\
\hline Klebsiella pneumoniae (ATCC 27736) & $3.00 \pm 0.00$ & NA & NA & NA & NA & NA \\
\hline Pseudomonas aeruginosa (ATCC 27853) & $5.00 \pm 0.00$ & NA & NA & NA & NA & NA \\
\hline Escherichia coli (ATCC 25922) & $6.00 \pm 0.00$ & NA & NA & NA & NA & NA \\
\hline Proteus vulgaris (ATCC 6380) & $6.33 \pm 0.47$ & NA & $1.67 \pm 0.45$ & $1.44 \pm 0.50$ & $0.11 \pm 0.31$ & NA \\
\hline
\end{tabular}


Table 1. Cont.

\begin{tabular}{|c|c|c|c|c|c|c|}
\hline Proteus mirabilis (ATCC 7002) & $6.00 \pm 0.00$ & NA & $2.00 \pm 0.00$ & $1.78 \pm 0.42$ & NA & NA \\
\hline Acinetobacter baumannii (ATCC 19606) & $4.00 \pm 0.00$ & NA & $1.00 \pm 0.00$ & $0.89 \pm 0.57$ & NA & NA \\
\hline Enterobacter aerogenes (ATCC 13048) & $3.00 \pm 0.00$ & NA & NA & NA & NA & NA \\
\hline Enterobacter cloacae (ATCC 13047) & $3.00 \pm 0.00$ & NA & $0.44 \pm 0.47$ & $0.22 \pm 0.42$ & NA & NA \\
\hline
\end{tabular}

All S. hillii extracts were antibacterial against Gram-positive strains. P. vulgaris, P. mirabilis, A. baumannii, and E. cloacae were susceptible to methanol and ethanol extracts derived from $S$. hillii. Overall, the methanol and ethanol extracts were the most efficacious against the bacterial strains tested. ZOIs (zones of inhibition) were measured as the radius from the edge of the well to the edge of the clear zone $(\mathrm{mm})$ and are expressed as the mean of triplicates \pm standard error (SEM). SXT: trimethoprim + sulfamethoxazole. NA: no activity. Negative control: sterile milli-Q water or $10 \%$ isopropanol $(0 \pm 0.0 \mathrm{~mm})$. MSSA: methicillin-sensitive Staphylococcus aureus. MRSA: methicillin-resistant Staphylococcus aureus. Standard antibiotic discs were used as positive controls, whereby trimethoprim $(1.25 \mu \mathrm{g})$ + sulfamethoxazole $(23.75 \mu \mathrm{g})$ acted as the control for both MRSA isolates, S. epidermidis, S. saprophyticus, P. vulgaris, and P. mirabilis; penicillin G (10 $\mu \mathrm{g})$ for MSSA; erythromycin (15 $\mu \mathrm{g})$ for $B$. cereus and B. subtilis; gentamicin $(10 \mu \mathrm{g})$ for K. pneumoniae, E. coli, P. aeruginosa, A. baumannii, E. aerogenes, and E. clocae; teicoplanin $(30 \mu \mathrm{g})$ for E. faecalis, E. casseliflavus, and E. gallinarum; and linezolid (30 $\mathrm{gg})$ was used for E. faecium. Test performed in triplicate and repeated three times $(n=3)$.

\subsection{Minimum Inhibitory Concentration (MIC) of Primary Extract}

MIC values were determined for all five $S$. hillii-derived extracts against the bacterial strains, which were shown to be susceptible from the previous WDAs (Table 2). MIC values for the tested extracts ranged from 0.63 to $10 \mathrm{mg} / \mathrm{mL}$. Methanolic and ethanolic extracts produced the lowest MIC values compared to the other extracts, although none were shown to impede the growth of E. faecalis, E. faecium, or E. gallinarum at a concentration of $10 \mathrm{mg} / \mathrm{mL}$. Further, none of the bacteria screened were susceptible to hexane extracts at the highest concentration tested.

Table 2. MIC of S. hillii methanol and ethanol against bacterial strains.

\begin{tabular}{|c|c|c|c|c|c|c|}
\hline \multirow{2}{*}{ Bacterial Strain } & \multirow{2}{*}{$\begin{array}{l}\text { Antibiotic Standard } \\
\qquad(\mu \mathrm{g} / \mathrm{mL})\end{array}$} & \multicolumn{5}{|c|}{ S. hillii Extracts (mg/mL) } \\
\hline & & Methanol & Ethanol & Aqueous & Isopropanol & Hexane \\
\hline \multicolumn{7}{|l|}{ Gram-positive bacteria } \\
\hline Bacillus cereus (ATCC 14579) & 5.00 & 1.25 & 2.50 & 10.00 & 5.00 & $>10.00$ \\
\hline MSSA (NCTC 6571) & $5.00 *$ & 1.25 & 1.25 & 5.00 & 5.00 & $>10.00$ \\
\hline MRSA (QUT 1113) & $5.00 *$ & 0.63 & 1.25 & 2.50 & 2.50 & $>10.00$ \\
\hline MRSA (ATCC 33591) & $5.00 *$ & 0.63 & 0.63 & 2.50 & 2.50 & $>10.00$ \\
\hline Bacillus subtilis (QUT 0535) & 2.50 & 5.00 & 5.00 & ND & 10.00 & $>10.00$ \\
\hline Staphylococcus epidermidis (QUT 0613) & $4.00 *$ & 0.63 & 0.63 & 2.50 & 2.50 & ND \\
\hline Staphylococcus saprophyticus (QUT 0703) & $30.00 *$ & 1.25 & 1.25 & 5.00 & ND & $>10.00$ \\
\hline \multicolumn{7}{|l|}{ Gram-negative bacteria } \\
\hline Proteus vulgaris (ATCC 6380) & 5.00 & 1.25 & 1.25 & ND & ND & ND \\
\hline Proteus mirabilis (ATCC 7002) & 5.00 & 1.25 & 2.50 & ND & ND & ND \\
\hline Acinetobacter baumannii (ATCC 19606) & $10.00 *$ & 2.50 & 2.50 & ND & ND & ND \\
\hline Enterobacter cloacae (ATCC 13047) & $20.00 *$ & 1.25 & 1.25 & ND & ND & ND \\
\hline
\end{tabular}

Staphylococcal species exhibited the greatest susceptibility to $S$. hillii extracts. MIC values were determined by the lack of INT reduction to INT formazan measured at $550 \mathrm{~nm}$ and are expressed as the mean of triplicates. ND: not determined. SXT: trimethoprim + sulfamethoxazole. MSSA: methicillin-sensitive Staphylococcus aureus. MRSA: methicillin-resistant Staphylococcus aureus. *: MIC values obtained from EUCAST (The European Committee on Antimicrobial Susceptibility Testing). Standard antibiotics were used as positive controls, whereby trimethoprim $(1.25 \mu \mathrm{g})$ acted as the control for both MRSA isolates, S. epidermidis, S. saprophyticus, P. vulgaris, and P. mirabilis; penicillin G $(10 \mu \mathrm{g})$ for MSSA; erythromycin $(15 \mu \mathrm{g})$ for B. cereus and B. subtilis; gentamicin (10 $\mu \mathrm{g})$ for K. pneumoniae, A. baumannii, and E. clocae. Test performed in triplicate and repeated three times $(\mathrm{n}=3)$.

\subsection{Minimum Bactericidal Concentration (MBC) of Primary Extracts}

From the MIC studies, methanolic and ethanolic extracts were identified as the most potent. Hence, both were selected to determine MBC values, which ranged from 5 to $20 \mathrm{mg} / \mathrm{mL}$ (Table 3). Of all the bacteria tested, Staphylococcal strains were found to be most susceptible to the two extracts. 
Table 3. MBC of S. hillii leaf extracts on screened bacterial strains.

\begin{tabular}{|c|c|c|c|}
\hline \multirow{2}{*}{ Bacterial Strain } & \multirow{2}{*}{$\begin{array}{l}\text { Tested Concentration of the Standard Antibiotic } \\
\qquad(\mathrm{mg} / \mathrm{mL})\end{array}$} & \multicolumn{2}{|c|}{ MBC of $S$. hillii Extracts $(\mathrm{mg} / \mathrm{mL})$} \\
\hline & & Methanol & Ethanol \\
\hline \multicolumn{4}{|l|}{ Gram-positive bacteria } \\
\hline Bacillus cereus (ATCC 14579) & 1.0 & 15.0 & 20.0 \\
\hline MSSA (NCTC 6571) & 1.0 & 5.0 & 5.0 \\
\hline MRSA (ATCC 33591) & 1.0 & 7.5 & 7.5 \\
\hline MRSA (QUT 1113) & 1.0 & 7.5 & 5.0 \\
\hline Bacillus subtilis (QUT 0535) & 1.0 & 15.0 & 15.0 \\
\hline Staphylococcus epidermidis (QUT 0613) & 1.0 & 5.0 & 5.0 \\
\hline Enterococcus faecalis (QUT 1105) & 1.0 & $>20.0$ & $>20.0$ \\
\hline Enterococcus faecium (QUT 1101) & 1.0 & $>20.0$ & $>20.0$ \\
\hline Enterococcus gallinarum (ATCC 13048) & 1.0 & $>20.0$ & $>20.0$ \\
\hline Enterococcus casseliflavus (ATCC 25788) & 1.0 & $>20.0$ & $>20.0$ \\
\hline Staphylococcus saprophyticus (QUT 0703) & 1.0 & 5.0 & 5.0 \\
\hline \multicolumn{4}{|l|}{ Gram-negative Bacteria } \\
\hline Proteus vulgaris (ATCC 7002) & 1.0 & $>20.0$ & $>20.0$ \\
\hline Proteus mirabilis (ATCC 6380) & 1.0 & $>20.0$ & $>20.0$ \\
\hline Acinetobacter baumannii (ATCC 19606) & 1.0 & $>20.0$ & $>20.0$ \\
\hline Enterobacter cloacae (ATCC 13047) & 1.0 & $>20.0$ & $>20.0$ \\
\hline
\end{tabular}

Staphylococcal species exhibited the greatest susceptibility to all the S. hillii extracts. Gram-negative strains exhibited resistance to methanol and ethanol $S$. hillii extracts at $20.0 \mathrm{mg} / \mathrm{mL}$. MBC values were defined as the lowest concentration that ceased bacterial growth on the Mueller-Hinton agar/tryptic soy agar and are expressed as the mean of triplicates. SXT: trimethoprim + sulfamethoxazole. MSSA: methicillin-sensitive Staphylococcus aureus. MRSA: methicillin-resistant Staphylococcus aureus. ND: not determined. Standard antibiotics were used as positive controls, whereby trimethoprim $(1.25 \mu \mathrm{g})+$ sulfamethoxazole $(23.75 \mu \mathrm{g})$ acted as the control for both MRSA isolates, S. epidermidis, S. saprophyticus, P. vulgaris, and P. mirabilis; penicillin G (10 $\mu \mathrm{g})$ for MSSA; erythromycin $(15 \mu \mathrm{g})$ for B. cereus and B. subtilis; gentamicin $(10 \mu \mathrm{g})$ for A. baumannii and E. clocae; teicoplanin $(30 \mu \mathrm{g})$ for E. faecalis, E. casseliflavus, and E. gallinarum; and linezolid $(30 \mu \mathrm{g})$ was used for E. faecium. Test performed in triplicate and repeated three times $(n=3)$.

\subsection{Biofilm Eradication Activity of S. hillii Extracts}

Based on antibacterial data obtained from previous experiments in which the methanol extract was most efficacious, its biofilm eradication ability was assessed. The average percentage reduction of colony forming units (CFU) was measured at different concentrations ranging between 0.3 and $10 \mathrm{mg} / \mathrm{mL}$. The minimum biofilm eradication concentration (MBEC) of MRSA (ATCC 33591) when treated with the S. hillii-derived methanolic extract was $2.5 \mathrm{mg} / \mathrm{mL}$ (Figure 1).

\subsection{Antimicrobial Activity of Primary Column Fractions of S. hillii-Derived Methanolic Extract}

Due to antimicrobial activity, the methanolic extract was fractionated by column chromatography using a dichloromethane:methanol gradient system. This resulted in 11 fractions that were subsequently screened against B. cereus (ATCC 14579), MRSA (ATCC 33591), P. vulgaris (ATCC 7002), A. baumannii (ATCC 19606), and E. cloacae (ATCC 13047) at $50 \mathrm{mg} / \mathrm{mL}$ via the WDA (Figure 2). Both $70 \%$ and $80 \%$ methanolic fractions were highly effective against the tested bacteria; however, the overall efficacy was significantly lower compared to the antibiotic standard. B. cereus (ATCC 14579) was found to be resistant to all methanol fractions at $50 \mathrm{mg} / \mathrm{mL}$. Fractions containing 30-80\% methanol were shown to inhibit the growth of MRSA (ATCC 33591), P. vulgaris (ATCC 7002), A. baumannii (ATCC 19606), and E. cloacae (ATCC 13047), although at differing degrees. Moreover, the $90-100 \%$ methanolic fractions inhibited the growth of MRSA (ATCC 33591), while the 30\% fraction inhibited A. baumannii (ATCC 19606). However, the antimicrobial activity of the respective standard antibiotic control was significantly higher compared to all S. hillii-derived methanol fractions at the concentration tested. 
Percentage inhibition of biofilm forming MRSA (ATCC 33591) CFU

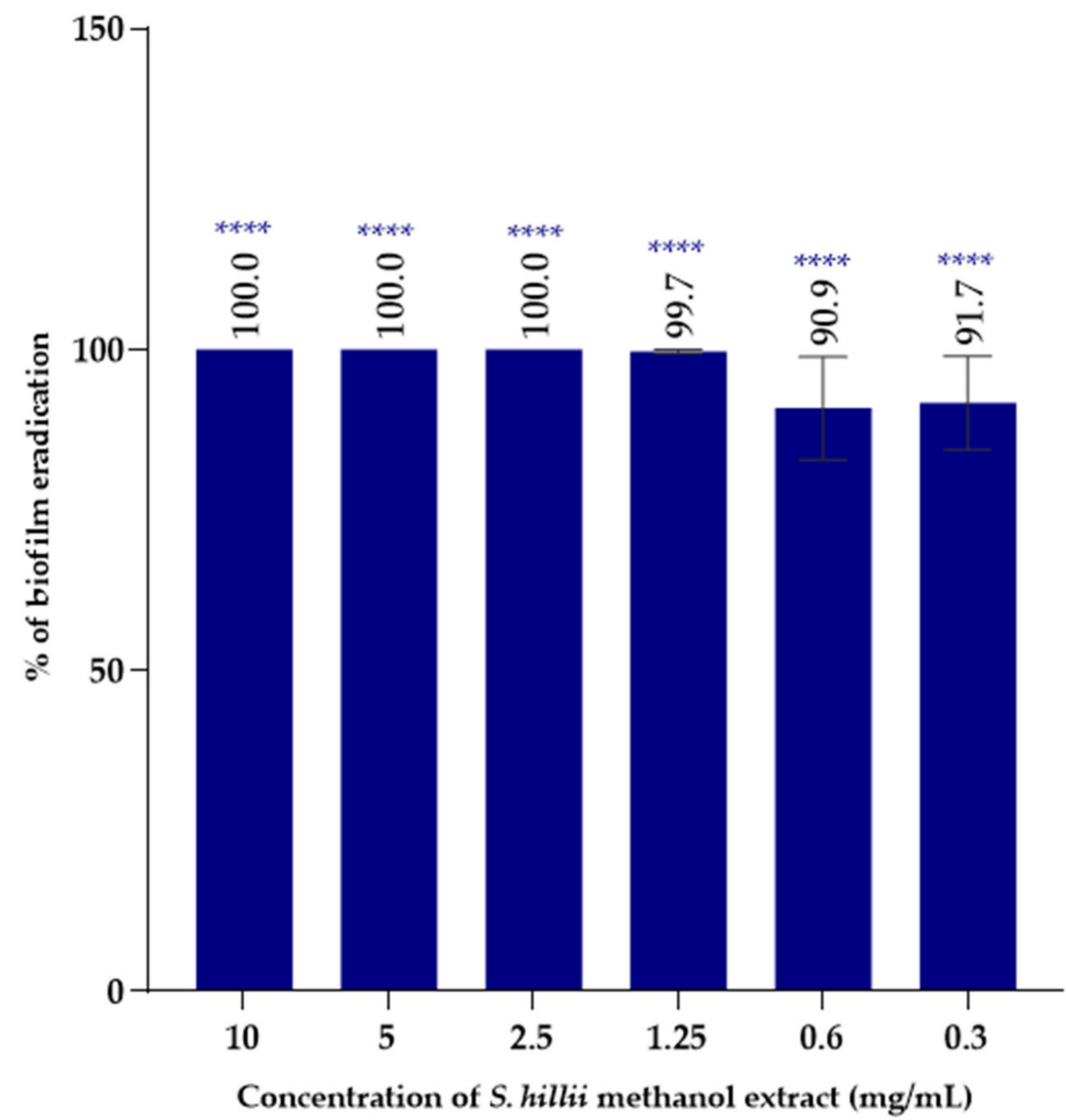

Figure 1. Biofilm eradication activity of $S$. hillii methanol extract against biofilm-forming MRSA (ATCC 33591) strain. The minimum biofilm eradication concentration (MBEC) of the S. hillii methanolic extract for MRSA (ATCC 33591) was $2.5 \mathrm{mg} / \mathrm{mL}$. The average percentage inhibition of colony forming units (CFU) was measured by direct enumeration of viable MRSA colony forming units using ImageJ software and are expressed as the percentage mean of triplicates $(n=3) \pm$ standard error (SEM). MRSA: methicillin-resistant Staphylococcus aureus. Significance levels ${ }^{* * * *} p<0.0001$ compared to untreated control.

\subsection{Isolation of Compounds from Primary Methanolic Fractions}

Among the primary 30\%, 70\%, and 80\% column fractions, all demonstrated antimicrobial activity against bacterial strains that are renowned for being highly resistant to antibiotics. As such, they were further fractionated using preparative HPLC. Due to similarities in HPLC chromatogram profiles and antibacterial activity, the $80 \%$ and $70 \%$ fractions were pooled. Quercetin-3-O- $\beta$-D-glucuronide was isolated from the pooled fraction (Figure 3), whereas shikimic acid was isolated from the 30\% methanolic fraction (Figure 4).

Eleven milligrams of quercetin-3-O- $\beta$-D-glucuronide was isolated (Figure 3A), with structure elucidation based on the analyses of ${ }^{1} \mathrm{H}$ and ${ }^{13} \mathrm{C}$ NMR (Table 4), correlated spectroscopy (COSY), heteronuclear multiple bond correlation (HMBC), and heteronuclear single quantum coherence (HSQC) NMR experiments. The NMR spectra are provided in the Supplementary Materials File 1. The aromatic region of the ${ }^{1} \mathrm{H}-\mathrm{NMR}$ spectrum of the specified fraction revealed a doublet for two protons at 6.74 and $7.50 \mathrm{ppm}$, which were assigned to $\mathrm{H}-5^{\prime}$ and $\mathrm{H}-6^{\prime}$ hydrogens of ring A, respectively, whereas the singlet at $7.58 \mathrm{ppm}$ was assigned to the $\mathrm{H}-2^{\prime}$ hydrogen of ring $\mathrm{A}$. A set of doublets at 6.10 and $6.29 \mathrm{ppm}$ in the aromatic region were assigned to H-6 and H-8 hydrogens of ring $\mathrm{C}$, respectively. In the aliphatic region of the spectrum, three triplets at $3.35,3.42$, and 3.47 ppm were assigned to $\mathrm{H}-4^{\prime \prime}, \mathrm{H}-5^{\prime \prime}$, and $\mathrm{H}-3^{\prime \prime}$ of the glycosylated sugar moiety, respectively. The key 
anomeric proton appeared at $5.23 \mathrm{ppm}$. The ${ }^{13} \mathrm{C}$ NMR spectrum confirmed that there were 15 carbons in the molecule. Further characterization by HSQC- and HMBC-2D-NMR revealed carbon-hydrogen $(\mathrm{C}-\mathrm{H})$ single bond correlations and multiple bond correlations for the aromatic region. Key correlations from HSQC revealed that H-2' (7.58), H-5' (6.74), and $\mathrm{H}-6^{\prime}$ (7.50) were attached to C-2' (115.9), C-5' (114.6), and C-6' (121.9) of ring A; H-6 (6.10) and H-8 (6.29) to C-6 (98.5) and C-8 (93.3) of ring C; and H-2" (5.90), H-3" (5.90), $\mathrm{H}-4^{\prime \prime}$ (5.90), and $\mathrm{H}-5^{\prime \prime}$ (5.90) to C-2" (76.2), C- $3^{\prime \prime}$ (71.5), C- $4^{\prime \prime}$ (76.2), and C- $5^{\prime \prime}$ (74.0) of the sugar moiety, respectively.

Antibacterial effects of S. hillii methanol column fractions

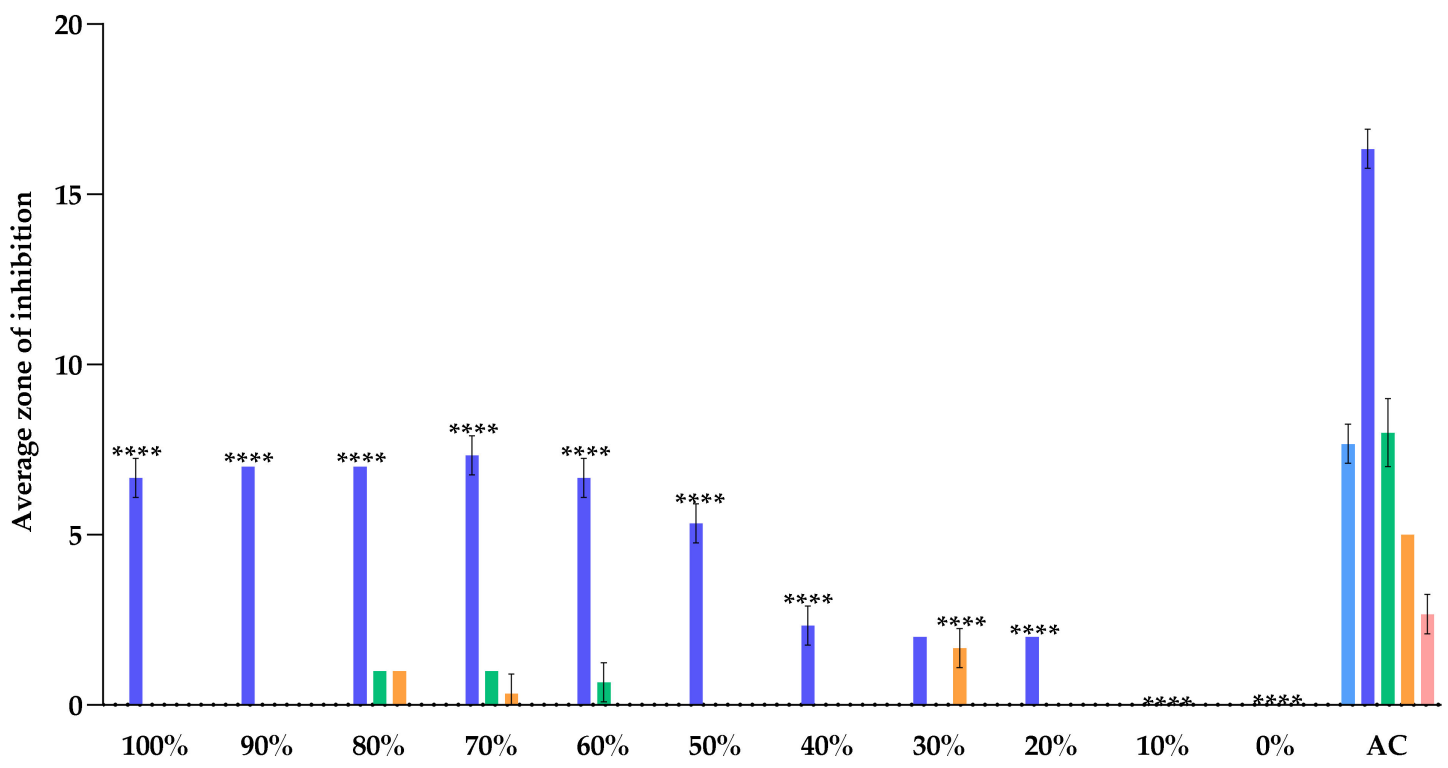

S. hillii methanol column fractions

Figure 2. Antibacterial effects of $S$. hillii column fractions against B. cereus, MRSA, P. vulgaris, A. baumannii, and E. cloacae at $10 \mathrm{mg} / \mathrm{mL}$. B. cereus (ATCC 14579) was resistant to all methanol fractions at the tested concentration. $20-100 \%$ fractions showed antibacterial effects against MRSA (ATCC 33591). The 30\% fraction elicited the highest antibacterial effects against A. baumannii (ATCC 19606). However, the antibacterial activities of all the fractions were significantly low compared to the antibiotic standards $(p<0.0001)$. Eleven fractions were tested against five bacterial species, which were shown to be susceptible to the $S$. hillii methanol extract in the preliminary antibacterial screening. ZOI (zone of inhibition) was measured using the radius from the edge of the well to the edge of the clear zone $(\mathrm{mm})$ and are expressed as the mean of triplicates \pm standard error (SEM). Significance levels ${ }^{* * * *} p<0.0001$ compared to antibiotic control (AC). MRSA: methicillin-resistant Staphylococcus aureus. AC: antibiotic control.

The key HMBC three-bond correlations were from H-6 to C-5 (161.0), C-7 (164.6), C-8 (93.3), and C-4a (104.2); H-8 to C-6 (98.5), C-7 (164.6), C-8a (157.0), and C-4a (104.2); H-2' to C-2 (157.6), C-1' (121.4), C-3' (144.6), C-4' (148.5), and C-6' (121.9); H-5' to C-1' (121.4), C-3' (144.6), C-4' (148.5), and C-6' (121.9); and H-6' to C-2 (157.6), C-2' (115.9), C-4' (148.5), and C-5' (114.6) (Figure 3B). A key correlation was observed from H-6' to C-3 (157.6), indicating that $C-3$ was glycosylated. In addition, the obtained proton NMR values are consistent with the published literature [14]. These HMBC correlations verified the structure as quercetin-3-O- $\beta$-D-glucuronide. The ESI-MS produced a mass ion peak in negative mode at $m / z$ 477.0677, further confirming the structure. 


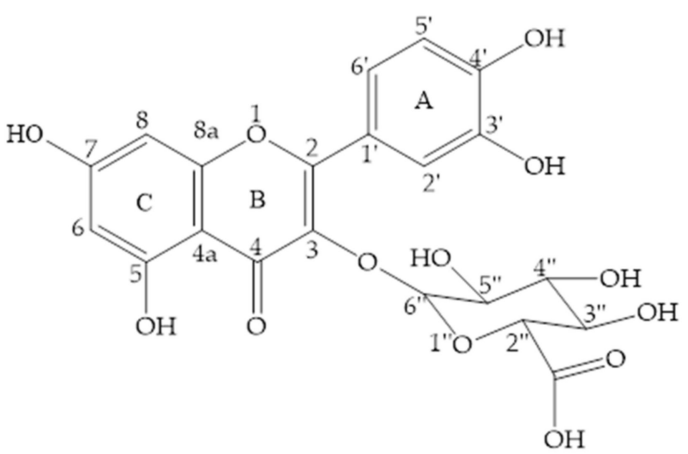

(A)

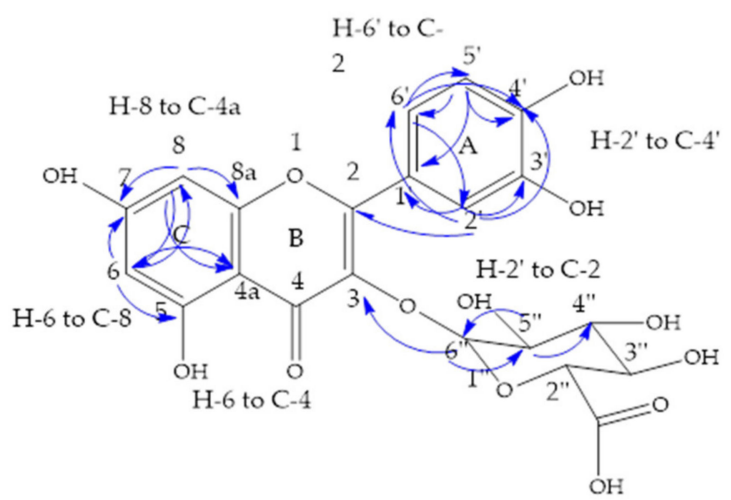

(B)

Figure 3. (A) Chemical structure of quercetin-3-O- $\beta$-D-glucuronide isolated from combined $70 \%$ and $80 \%$ fraction of the $S$. hillii methanol extract. (B) Key correlations of the heteronuclear multiple bond correlation (HMBC) of quercetin-3-O- $\beta$-D-glucuronide (images: ChemDraw 18.1).<smiles>O=C(O)C1=CC(O)C(O)C(O)C1</smiles>

(A)

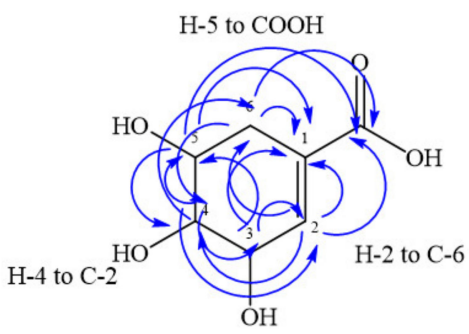

(B)

Figure 4. (A) Chemical structure of shikimic acid isolated from $30 \%$ fraction of the S. hillii methanol extract. (B) Key correlations of the heteronuclear multiple bond correlation (HMBC) of shikimic acid (images: ChemDraw 18.1).

A total of $586 \mathrm{mg}$ of shikimic acid was isolated (Figure 4A), with the structure determined using the same analytical techniques previously used to identify quercetin (Table 5). The NMR spectra are provided in the Supplementary Materials File 1. In the ${ }^{1} \mathrm{H}$ spectrum, singlets at 6.58 and 4.20 ppm were assigned to $\mathrm{H}-2$ and $\mathrm{H}-3$ protons, and multiplets at 3.52-3.54 and 3.81-3.84 ppm were assigned to H-4 and H-5 protons of the compound, respectively. The methylene protons at $\mathrm{H}-6$ of shikimic acid appeared as doublets at 1.99 and $2.40 \mathrm{ppm}$. The ${ }^{13} \mathrm{C}$ NMR spectrum confirmed that seven carbons are contained within the molecule. Further characterization by HSQC- and HMBC-2DNMR revealed carbonhydrogen $(\mathrm{C}-\mathrm{H})$ single bond correlations and multiple bond correlations for the assigned structure. Key correlations from HSQC revealed that H-2 (6.58), H-3 (4.20), H-4 (3.52-3.54), H-5 (3.81-3.84), H-6a (2.40), and H-6b (1.99) were attached to C-2 (138.4), C-3 (65.9), C-4 (70.9), C-5 (67.2), C-6a (30.6), and C-6b (30.6), respectively.

The key HMBC correlations were from H-2 to C-1 (129.5), C-4 (70.9), C-6 (30.6), and COOH (168.8); H-3 to C-1 (129.5), C-2 (138.4), and C-5 (67.2); H-4 to C-2 (138.4), C-3 (65.9), C5 (67.2), and C-6 (30.6); H-5 to C-1 (129.5), C-3 (65.9), C-4 (70.9), and COOH (168.8); H-6a and H-6b to C-1 (129.5), C-2 (138.4), C-4 (70.9), and C-5 (67.2) (Figure 4B). HMBC correlations confirmed the structure as shikimic acid, which was further supported as a mass ion peak in negative mode at $m / z 174.05$ was observed during the ESI-MS analysis. In addition, the obtained proton NMR values are consistent with the published literature $[15,16]$. 
Table 4. NMR data for compound quercetin-3-O- $\beta$-D-glucuronide in deuterated methanol (MeOD).

\begin{tabular}{|c|c|c|c|}
\hline Carbon Number & ${ }^{1} \mathbf{H}$ & ${ }^{13} \mathrm{C}$ & HMBC $\left({ }^{13} \mathrm{C}\right)$ \\
\hline \multicolumn{4}{|l|}{1} \\
\hline 2 & & 157.6 & \\
\hline 3 & & 134.0 & \\
\hline 4 & & 177.8 & \\
\hline $4 a$ & & 104.2 & \\
\hline 5 & & 161.6 & \\
\hline 6 & $\mathrm{H}(\mathrm{d}) 6.10$ & 98.5 & C-5, C-7, C-8 and C-4a \\
\hline 7 & & 164.6 & \\
\hline 8 & $\mathrm{H}(\mathrm{d}) 6.29$ & 93.3 & C-6, C-4a, C-8a, and C-7 \\
\hline $8 a$ & & 157.0 & \\
\hline $1^{\prime}$ & & 121.4 & \\
\hline $2^{\prime}$ & $\mathrm{H}$; (s) 7.58 & 115.9 & $\mathrm{C}-2, \mathrm{C}-1^{\prime}, \mathrm{C}-6^{\prime}, \mathrm{C}-3^{\prime}$ and $\mathrm{C}-4^{\prime}$ \\
\hline $3^{\prime}$ & & 144.5 & \\
\hline $4^{\prime}$ & & 148.5 & \\
\hline $5^{\prime}$ & $\mathrm{H} ;$ (d) 6.74 & 114.6 & $C-1^{\prime}, C-6^{\prime}, C-4^{\prime}$ and $C-3^{\prime}$ \\
\hline $6^{\prime}$ & $\mathrm{H} ;(\mathrm{d}) 7.50$ & 121.9 & $C-2, C-2^{\prime}, C-4^{\prime}$ and $C-5^{\prime}$ \\
\hline \multicolumn{4}{|r|}{ - } \\
\hline $2^{\prime \prime}$ & $\mathrm{H}$; (d) 3.64 & 76.2 & \\
\hline $3^{\prime \prime}$ & $\mathrm{H} ;(\mathrm{t}) 3.47$ & 71.5 & \\
\hline $4^{\prime \prime}$ & $\mathrm{H} ;(\mathrm{t}) 3.35$ & 76.2 & \\
\hline $5^{\prime \prime}$ & $\mathrm{H} ;(\mathrm{t}) 3.42$ & 74.0 & $C-4^{\prime \prime}$, and C-6" \\
\hline $6^{\prime \prime}$ & H; (d) 5.23 & 102.8 & $C-3$ and $C-5^{\prime \prime}$ \\
\hline
\end{tabular}

${ }^{1} \mathrm{H}$ NMR $(600 \mathrm{MHz}, \mathrm{MeOD}) \delta 7.58\left(\mathrm{~s},{ }^{1} \mathrm{H}\right), 7.50\left(\mathrm{~d}, \mathrm{~J}=8.5 \mathrm{~Hz},{ }^{1} \mathrm{H}\right), 6.74\left(\mathrm{~d},{ }^{1} \mathrm{H}\right), 6.29\left(\mathrm{~d}, \mathrm{~J}=2.0 \mathrm{~Hz},{ }^{1} \mathrm{H}\right), 6.10$ $\left(\mathrm{d}, \mathrm{J}=11.6 \mathrm{~Hz},{ }^{1} \mathrm{H}\right), 5.23\left(\mathrm{~d},{ }^{1} \mathrm{H}\right), 3.64\left(\mathrm{~d},{ }^{1} \mathrm{H}\right), 3.47\left(\mathrm{t},{ }^{1} \mathrm{H}\right), 3.42\left(\mathrm{t},{ }^{1} \mathrm{H}\right), 3.35\left(\mathrm{t},{ }^{1} \mathrm{H}\right) .{ }^{13} \mathrm{C}$ NMR $(150 \mathrm{MHz}, \mathrm{MeOD}) \delta$ $71.5,74.0,76.2,93.3,98.5,102.8,104.2,114.6,115.9,121.4,121.9,134.0,144.5,148.5,157.0,157.6,161.6,164.6,177.8$.

Table 5. NMR data for compound shikimic acid in deuterated dimethyl sulfoxide (DMSO).

\begin{tabular}{cccc}
\hline Carbon Number & ${ }^{\mathbf{1}} \mathbf{H}$ & ${ }^{\mathbf{1 3}} \mathbf{C}$ & HMBC $\left({ }^{\mathbf{1 3}} \mathbf{C}\right)$ \\
\hline 1 & & 129.5 & \\
2 & $\mathrm{H}(\mathrm{s}) 6.58$ & 138.4 & $\mathrm{C}-1, \mathrm{C}-4, \mathrm{C}-6$ and COOH \\
3 & $\mathrm{H}(\mathrm{s}) 4.20$ & 65.9 & $\mathrm{C}-1, \mathrm{C}-2$ and C-5 \\
4 & $\mathrm{H}(\mathrm{m}) 3.52-3.54$ & 70.9 & $\mathrm{C}-2, \mathrm{C}-3, \mathrm{C}-5$ and C-6 \\
5 & $\mathrm{H}(\mathrm{m}) 3.81-3.84$ & 67.2 & $\mathrm{C}-1, \mathrm{C}-3, \mathrm{C}-4$ and COOH \\
$6 \mathrm{a}$ & $\mathrm{H}(\mathrm{d}) 2.40$ & 30.6 & $\mathrm{C}-1, \mathrm{C}-2, \mathrm{C}-4, \mathrm{C}-5$ and COOH \\
$6 \mathrm{~b}$ & $\mathrm{H}(\mathrm{d}) 1.99$ & 30.6 & $\mathrm{C}-1, \mathrm{C}-2, \mathrm{C}-4, \mathrm{C}-5$ and COOH \\
$\mathrm{COOH}$ & - & 168.8 & - \\
\hline
\end{tabular}

${ }^{1} \mathrm{H}$ NMR $\left(600 \mathrm{MHz}\right.$, DMSO-d6) $\delta 6.58\left(\mathrm{~s},{ }^{1} \mathrm{H}\right), 4.20\left(\mathrm{~s},{ }^{1} \mathrm{H}\right), 3.52-3.54\left(\mathrm{~m},{ }^{1} \mathrm{H}\right), 3.81-3.84\left(\mathrm{~d},{ }^{1} \mathrm{H}\right), 2.40\left(\mathrm{~d},{ }^{1} \mathrm{H}\right), 1.99$ $\left(\mathrm{d},{ }^{1} \mathrm{H}\right) .{ }^{13} \mathrm{C}$ NMR $(150 \mathrm{MHz}, \mathrm{DMSO}-\mathrm{d} 6) \delta 30.6,65.9,67.2,70.9,129.5,138.4,168.8$.

\subsection{Antimicrobial Activity of Isolated Compounds from the S. hillii Methanolic Extract}

Quercetin-3-O- $\beta$-D-glucuronide and shikimic acid were screened against eight bacteria, including several ESKAPE pathogens. MIC values ranged from 0.78 to $200 \mu \mathrm{g} / \mathrm{mL}$ (Table 6). Both compounds exhibited antibacterial effects against the target bacteria, although at varying concentrations. Shikimic acid inhibited the growth of E. faecalis (QUT 1105), E. cloacae (ATCC 13047), and P. aeruginosa (ATCC 27853) at $200 \mu \mathrm{g} / \mathrm{mL}$. Similarly, quercetin-3-O- $\beta$-D-glucuronide was effective against $P$. vulgaris (ATCC 6380), $P$. aeruginosa (ATCC 27853), and E. cloacae (ATCC 13047) at the same concentration, with the compound exerting potent antimicrobial activity against $E$. faecalis (QUT 1105) (MIC-0.78 $\mu \mathrm{g} / \mathrm{mL}$ ). In general, B. cereus (ATCC 14579), MRSA (ATCC 33591), A. baumannii (ATCC 19606), and $K$. pneumoniae (ATCC 27736) were the most resistant to the isolated compounds. 
Table 6. MIC values of isolated compounds from S. hillii methanol extract.

\begin{tabular}{|c|c|c|c|c|}
\hline \multirow{2}{*}{ Bacterial Strain } & \multicolumn{2}{|c|}{ Antibiotic Standard } & \multicolumn{2}{|c|}{ Compounds $(\mu \mathrm{g} / \mathrm{mL})$} \\
\hline & Name & $\operatorname{MIC}(\mu \mathrm{g} / \mathrm{mL})$ & Quercetin & Shikimic Acid \\
\hline \multicolumn{5}{|l|}{ Gram-positive bacteria } \\
\hline Bacillus cereus (ATCC 14579) & Erythromycin & 5.0 & $>200.0$ & $>200.0$ \\
\hline MRSA (ATCC 33591) & SXT & $5.0 *$ & $>200.0$ & $>200.0$ \\
\hline Enterococcus faecalis (QUT 1105) & Teicoplanin & $30.0 *$ & 0.78 & 200.0 \\
\hline \multicolumn{5}{|l|}{ Gram-negative bacteria } \\
\hline Proteus vulgaris (ATCC 6380) & SXT & 5.0 & 200.0 & $>200.0$ \\
\hline Acinetobacter baumannii (ATCC 19606) & Gentamicin & 10.0 * & $>200.0$ & $>200.0$ \\
\hline Enterobacter cloacae (ATCC 13047) & Gentamicin & $20.0 *$ & 200.0 & 200.0 \\
\hline Klebsiella pneumoniae (ATCC 27736) & Gentamicin & $2.0 *$ & $>200.0$ & $>200.0$ \\
\hline Pseudomonas aeruginosa (ATCC 27853) & Gentamicin & $10.0 *$ & 200.0 & 200.0 \\
\hline
\end{tabular}

Quercetin-3-O- $\beta$-D-glucuronide inhibited E. faecalis at $0.78 \mu \mathrm{g} / \mathrm{mL}, P$. vulgaris at $200 \mu \mathrm{g} / \mathrm{mL}$, P. aeruginosa at 200 $\mu \mathrm{g} / \mathrm{mL}$, and E. cloacae at $200 \mu \mathrm{g} / \mathrm{mL}$. Shikimic acid inhibited the growth of E. faecalis, E. cloacae, and P. aeruginosa at $200 \mu \mathrm{g} / \mathrm{mL}$. MIC values were determined by the lack of INT reduction to INT formazan measured at 550 $\mathrm{nm}$ and expressed as the mean of triplicates. Test performed in three replicates $(\mathrm{n}=3)$. SXT: trimethoprim + sulfamethoxazole. MSSA: methicillin-sensitive Staphylococcus aureus. MRSA: methicillin-resistant Staphylococcus aureus. *: MIC values obtained from EUCAST (The European Committee on Anti-microbial Susceptibility Testing).

\subsection{Predicted ADME Properties of the Isolated Compounds}

Given the potency of quercetin-3-O- $\beta$-D-glucuronide against E. faecalis (QUT 1105), in silico absorption, distribution, metabolism, and excretion (ADME) properties of the compound were determined (Table 7). Molecular weight, number of hydrogen bond acceptors and donors, molar refractivity, total polar surface area, and $\log \mathrm{P}$ are the most important physicochemical properties that are taken into account during drug development. Quercetin3 -O- $\beta$-D-glucuronide follows the recommended limit; however, the number of hydrogen bond donors and acceptors were shown to be outside the limit. Further, gastrointestinal (GI) absorption of the compound was also below the lower limit. According to the computationally derived properties, quercetin-3-O- $\beta$-D-glucuronide does not inhibit multiple cytochrome P450 enzymes, a group of enzymes essential for the metabolism of drugs.

Table 7. Physicochemical properties of quercetin-3-O- $\beta$-D-glucuronide.

\begin{tabular}{ccc}
\hline Descriptors & Values & Recommended Range \\
\hline Molecular weight & 478.36 & $150-500 \mathrm{~g} / \mathrm{mol}$ \\
Num. H-bond acceptors & 13 & 10 \\
Num. H-bond donors & 8 & 5 \\
Molar Refractivity & 110.77 & 40 to 130 \\
TPSA & $227.58 \mathrm{~A} 2$ & $20-130 \AA^{2}$ \\
Log Po/w & 1.13 & $<5$ \\
GI absorption & Low & - \\
CYP1A2 inhibitor & No & - \\
CYP2C19 inhibitor & No & - \\
CYP2C9 inhibitor & No & - \\
CYP2D6 inhibitor & No & - \\
CYP3A4 inhibitor & No & Maximum 4 \\
Lipinski rule violation & 2 &
\end{tabular}

\section{Discussion}

The genus Syncarpia has been used by the Yaegl community (New South Wales, Australia) for various medicinal purposes for many years [5]. Records concerning the use of S. hillii claim that the plant has the ability to heal sores and chronic ulcers, and the sap and ash from the leaves of related species, e.g., S. glomulifera, are said to have antiseptic properties $[5,9]$. Extracts derived from $S$. hillii showed antimicrobial activity against $80 \%$ 
of the bacterial strains screened, including pathogens that cause skin infections such as $S$. aureus. Ethanol and methanol extracts of $S$. hillii produced significantly higher activity against the bacterial species tested compared to other primary extracts. Further, both extracts demonstrated the highest inhibitory effects against Gram-positive Staphylococcal spp. compared to the remaining bacteria. Overall, Gram-negative bacteria were found to be impervious to $S$. hillii extracts regardless of the solvent used. Moreover, of the eight Gram-negative bacteria screened, only P. vulgaris (ATCC 7002), P. mirabilis (ATCC 6380), A. baumannii (ATCC 19606), and E. cloacae (ATCC 13047) were shown to be susceptible to the extracts; however, the effect was minimal. This result suggests that the compounds contained within the extracts, irrespective of solvent, are able to penetrate the peptidoglycan cell wall of Gram-positive bacteria and subsequently exert their bactericidal effects. Unlike Gram-negative bacteria, which, in addition to the same murein cell wall, also contain an outer membrane, it appears to be highly resistant to $S$. hillii-derived compounds.

Akter et al., tested the leaves of $S$. glomulifera against Gram-positive bacteria that included MSSA, MRSA, wild multi-drug-resistant S. aureus, and Gram-negative strains, P. aeruginosa and E. coli [5]. Following a similar extraction process as carried out in this study, the authors demonstrated that the ethanol extract of S. glomulifera was bactericidal against all Staphylococcus species screened [5]. These results mirrored our own to some extent; however, MIC values of the $S$. glomulifera extracts against the three $S$. aureus species were found to be 160 times more effective $(7.81 \mu \mathrm{g} / \mathrm{mL})$ compared to those $(1.25 \mathrm{mg} / \mathrm{mL})$ generated in our study. This suggests that even though both plants are members of the same family and share the same genus, S. glomulifera contains compounds that, overall, either have higher antibacterial potency, or the concentration of the bioactive(s) within the plant is much greater compared to $S$. hillii. In addition, morphogenetic, ontogenic, and environmental factors can also influence the biosynthesis and accumulation of plant compounds or secondary metabolites [17].

The MBC is the lowest concentration required to completely kill a pathogen. MBC values demonstrated in our study were much higher compared to the MIC values, thereby confirming that the extracts are bactericidal at a higher concentration and bacteriostatic at lower concentrations. The ratio of MBC to MIC provides information regarding the degree of bactericidal activity, i.e., a narrow ratio suggests higher activity, whereas a wide ratio is indicative of poor activity [18]. However, the bactericidal effect of a treatment is not only dependent upon antibiotic concentration, but also on the bacterial species being targeted, the inoculum density of the bacteria, as well as environmental conditions, such as $\mathrm{pH}$ and protein concentration [18]. The MBC values for the Gram-positive strains ranged between 5 and $20 \mathrm{mg} / \mathrm{mL}$ for the ethanol and methanol extracts, while the aqueous and isopropanol extracts were 10-20 mg/mL. Interestingly, the MBC value of the ethanol extract against various Staphylococcal strains was slightly lower than that of the methanol extract in contrast to the MIC values. This might be due to differences in detection methods used to determine the MIC and MBC values, as it has been reported that INT is reduced by different microorganisms at varying rates [19].

$P$. aeruginosa and $S$. aureus are reported to have the greatest number of biofilmproducing strains [20], although E. coli also generates biofilms 24-48 h post-infection [21,22]. Globally, $60 \%$ of all infected chronic wounds contain a biofilm $[23,24]$. Sessile bacterial cells in biofilms are considered highly resistant to heat and desiccation, acids, and antibiotics because of the high density of their extracellular polymeric structure [25]. A recent study showed that the resistance of biofilm-protected sessile bacterial cells are usually 10 to 1000 times higher compared to its planktonic counterparts [26]. The biofilm formation ability of MRSA has been identified as one of the major reasons behind its multidrug resistance [26]. MRSA exhibits major resistance to all available penicillins and most $\beta$-lactam drugs [26]. In our study, we aimed to determine whether the methanol extract obtained from $S$. hillii had the ability to impede biofilm formation as it had the greatest antibacterial activity of the plant fractions tested. The antibiofilm assay protocol was based on a direct enumeration of bacterial colony forming units produced by biofilm-forming MRSA (ATCC 
33591). The bacterium was treated with the S. hillii-derived methanolic extract over a concentration gradient. Colony counts of the treated MRSA were compared against an untreated control, and then the average percentage inhibition of CFUs was calculated. The MBEC of MRSA for the $S$. hillii methanol extract was found to be $2.5 \mathrm{mg} / \mathrm{mL}$. According to our study, it was evident that the concentration of the S. hillii methanolic extract needed to eradicate sessile MRSA cells is approximately fourfold higher compared with planktonic MRSA cells. However, due to the methodological differences used to detect the MIC and MBEC values, it is difficult to compare the magnitude of resistance of sessile bacteria in biofilms. There are several methods that are used to detect different parameters related to MRSA biofilm formation, although none are without drawbacks. For example, crystal violet and safranin assays are used to detect biofilm biomass, whilst fluorophores such as SYTO9 and propidium iodide (PI), based on live/dead cells, detect the metabolic rate of sessile bacteria within biofilms, and scanning electron microscope imaging is able to capture sessile bacteria trapped in a polysaccharide biofilm [27].

Based on the high efficacy of the S. hillii methanol extract, it was subjected to further fractionation and compound isolation. Of the 11 primary fractions resultant from the extract, eight were effective against at least one of the bacterial strains screened. Overall, methanol $70 \%$ and $80 \%$ fractions were the most efficacious against the bacterial strains tested, including MRSA (ATCC 33591). The 30\% methanolic fraction had a bactericidal effect on A. baumannii, although it was minimally effective against Gram-positive bacteria. A. baumannii is an important opportunistic pathogen that has caused global outbreaks of nosocomial infections [28]. Therefore, the 30\%, 70\%, and 80\% methanol fractions were subjected to further testing for potential compound isolation. Due to the similarities of the HPLC chromatogram profiles and antibacterial activity observed, the $80 \%$ and $70 \%$ methanol fractions were pooled. Quercetin-3-O- $\beta$-D-glucuronide was subsequently isolated from the combined fraction, while shikimic acid was isolated from the $30 \%$ methanol fraction. Of both compounds, quercetin-3-O- $\beta$-D-glucuronide was shown to be highly selective as it inhibited E. faecalis with a MIC value of $0.78 \mu \mathrm{g} / \mathrm{mL}$. Further, it impeded the growth of P. vulgaris (ATCC 6380), E. cloacae (ATCC 13047), and P. aeruginosa (ATCC $27853)$ at $200 \mu \mathrm{g} / \mathrm{mL}$. Shikimic acid also inhibited the growth of E. faecalis, E. cloacae, and $P$. aeruginosa at $200 \mu \mathrm{g} / \mathrm{mL}$. However, at a concentration of $10 \mathrm{mg} / \mathrm{mL}$, E. faecalis (QUT code 1105), P. vulgaris (QUT code 1105), E. cloacae (ATCC 13047), and P. aeruginosa (ATCC 27853) were impervious to the methanolic extract. The reason for this contrasting result may be due to the specific compounds responsible for the activity being at much lower concentrations in the extract during the initial screening.

Interestingly, MRSA (ATCC 33591), the most susceptible bacterial species to the $S$. hillii methanol extract, was not inhibited by either of the isolated compounds at $200 \mu \mathrm{g} / \mathrm{mL}$. This finding suggests that the synergism between compounds in a crude extract may result in loss of activity during the bioassay-guided fractionation process [29]. Two other studies determined the MIC value of quercetin against MRSA (ATCC 33591) [30] and a MRSA clinical isolate (ATCC 43300) [31] to be $300 \mu \mathrm{g} / \mathrm{mL}$ and $500 \mu \mathrm{g} / \mathrm{mL}$, respectively. Based on these reported results, the concentrations used in our study were too low to inhibit the growth of MRSA. Nonetheless, to verify this, future MIC assays should be performed at concentrations 2.5-fold higher. However, the amount of quercetin-3-O- $\beta$-D-glucuronide obtained in our study was relatively low, thereby severely limiting the concentration at which the compound could be tested, given its overall yield. Shikimic acid has also been reported to possess antibacterial activity against $S$. aureus at $2.5 \mathrm{mg} / \mathrm{mL}$ as it has the ability to damage cell membrane permeability [32]. This is relatively a very high concentration compared to what was used in our study. Further, the S. aureus strain (ATCC 6538) that Bai and colleagues [32] used is different to the bacterium we screened, hence making a direct comparison impossible.

Enterococci are important healthcare-associated pathogens that cause nosocomial infections [33,34] including urinary tract, intra-abdominal, pelvic and soft tissue infections [33]. Moreover, Enterococci are the second most common cause of bacteremia [33]. However, 
treatment of E. faecalis is challenging as the bacterium has developed intrinsic and acquired resistance to many antibiotics, including vancomycin, ampicillin, aminoglycosides, $\beta$-lactams, macrolides, cephalosporin, tetracycline, and fluoroquinolones [33,35]. Interestingly, quercetin-3-O- $\beta$-D-glucuronide tested in our study showed excellent inhibitory activity against $E$. faecalis (QUT code 1105) and has the potential for future drug development. As such, the physicochemical properties of quercetin-3-O- $\beta$-D-glucuronide were calculated using the SwissADME online tool. Some of the physicochemical properties such as number of hydrogen donor and acceptor bonds were outside the limit. This result is due to the presence of hydroxyl and phenolic groups contained within the structure. Further, 136 molecules are reported to have structural similarities (95-98\%) to quercetin-3-O- $\beta$-Dglucuronide within Scifinder. Hence, these molecules could be used initially to develop the structure-activity relationships of the compounds and to subsequently identify more potent analogs of quercetin-3-O- $\beta$-D-glucuronide, which can then be further optimized using classical synthetic medicinal chemistry techniques.

\section{Materials and Methods}

\subsection{Collection and Preparation of the Primary Leaf Extracts}

S. hillii mature leaves, confirmed by a botanist at Narangba nursery, Brisbane Queensland, were purchased from Daley Nurseries (Geneva, New South Wales, Australia), collected, dried, and ground into a fine powder using an herb grinder. The powder was then individually extracted using five different solvents of varying polarities. Aqueous, methanol (ThermoFisher Scientific, Massachusetts, MA, USA), and ethanol (ThermoFisher Scientific, Massachusetts, MA, USA) extracts of $S$. hillii were re-dissolved in milli-Q water (arium $^{\mathrm{TM}}$ pro, Sartorius, Germany), while the isopropanol (Merck Germany) and hexane (Merck, Germany) extracts were redissolved in 10\% isopropanol in milli-Q water to obtain a final extract concentration of $100 \mathrm{mg} / \mathrm{mL}$.

\subsection{Bacterial Cultures}

Bacterial cultures were either purchased from the ATCC via In Vitro Technologies (Melbourne, Australia) or obtained from Dr. Juliana Chiruta (QUT, Brisbane, Australia). Methicillin-resistant S. aureus (MRSA) (ATCC 33591 and clinical isolate QUT code 1113), MSSA (NCTC 6571), B. cereus (ATCC 14579), K. pneumoniae (ATCC 27736), E. coli (ATCC 25922), P. aeruginosa (ATCC 27853), B. subtilis (QUT code 0535), S. epidermidis (QUT code 0613), P. vulgaris (ATCC 6380), P. mirabilis (ATCC 7002), E. faecalis (QUT code 1105), E. faecium (QUT code 1101), multi-drug resistant A. baumannii (ATCC 19606), E. gallinarum (ATCC 49573), E. casseliflavus (ATCC 25788), E. aerogenes (ATCC 13048), E. cloacae (ATCC 13047), and S. saprophyticus (QUT code 0703) were used. Individual strains were streaked onto nutrient agar plates and incubated at $37^{\circ} \mathrm{C}$ for $24 \mathrm{~h}$, excluding B. subtilis, which was incubated at $28^{\circ} \mathrm{C}$ for $24 \mathrm{~h}$. Culture plates were stored at $2-8^{\circ} \mathrm{C}$ until required.

\subsection{Well Diffusion Assay (WDA)}

Before each antimicrobial test, a fresh subculture in Mueller-Hinton (MH) agar (Oxoid Ltd., Thebarton, Australia) was used to make the various bacterial saline suspensions. Briefly, one colony from the fresh bacterial subculture was suspended into $1 \mathrm{~mL}$ of sterile $0.9 \% \mathrm{w} / \mathrm{v}$ saline suspension and adjusted to equate to a $0.5 \mathrm{McFarland}$ standard. $\mathrm{MH}$ agar plates (ThermoFisher Scientific, Victoria, Australia) were then inoculated evenly with $200 \mu \mathrm{L}$ of an individual bacterial species using a sterile disposable spreader (SARSTEDT AG \& Co., Nümbrecht, Germany).

Wells were aseptically punched into the agar using a $6 \mathrm{~mm}$ biopsy punch (ThermoFisher Scientific, Victoria, Australia) and filled with $80 \mu \mathrm{L}$ of extracts at a concentration of $100 \mathrm{mg} / \mathrm{mL}$. Standard antibiotic discs (Oxoid Ltd., Hampshire, UK) were used as positive controls, whereby trimethoprim $(1.25 \mu \mathrm{g})+$ sulfamethoxazole $(23.75 \mu \mathrm{g})$ acted as the control for both MRSA isolates (QUT 1113 and ATCC 33591), S. epidermidis (QUT 0613), S. saprophyticus (QUT 0703), P. vulgaris (ATCC 6380), and P. mirabilis (ATCC 7002); penicillin 
G (10 $\mu \mathrm{g})$ was used for MSSA (NCTC 6571); erythromycin (15 $\mu \mathrm{g})$ was used for B. cereus (ATCC 14579) and B. subtilis (QUT 0535); gentamicin (10 $\mu \mathrm{g})$ was used for K. pneumoniae (ATCC 27736), E. coli (ATCC 25922), P. aeruginosa (ATCC 27853), A. baumannii (ATCC 19606), E. aerogenes (ATCC 13048), and E. clocae (ATCC 13047). Teicoplanin (30 $\mu \mathrm{g}$ ) was used for E. faecalis (QUT code 1105), E. casseliflavus (ATCC 25788), and E. gallinarum (ATCC 49573), while linezolid $(30 \mu \mathrm{g}$ ) was used for E. faecium (QUT code 1101). Plates were then incubated at $37^{\circ} \mathrm{C}$ for $24 \mathrm{~h}$ excluding $B$. subtilis (QUT 0535), which was incubated at $28^{\circ} \mathrm{C}$, and the subsequent $\mathrm{ZOI}$ (denoted as the radius from the edge of the well to outer margin of clear zone) was measured (mm).

\subsection{Minimum Inhibitory Concentration (MIC)}

MIC values of the plant extracts were determined using sterile 96-well plates (ThermoFisher Scientific, Victoria, Australia). An amount of $50 \mu \mathrm{L}$ of each bacterial suspension (0.5 McFarland standard) was added to each well. Cells with $50 \mu \mathrm{L}$ of MH broth and the corresponding bacterial suspension was used as the positive control. Conversely, bacterial suspensions with $50 \mu \mathrm{L}$ of $10 \mathrm{mg} / \mathrm{mL}$ of corresponding antibiotic were served as the antibiotic control. A diluted series of $50 \mu \mathrm{L}$ plant extracts in $\mathrm{MH}$ broth $(0.02-10 \mathrm{mg} / \mathrm{mL})$ was added to the treatment wells. Separately, $50 \mu \mathrm{L}$ of extract $(0.02-10 \mathrm{mg} / \mathrm{mL})$ in $\mathrm{MH}$ broth was added to serve as the background control of the extracts.

The 96-well plates were subsequently sealed and incubated overnight at $37^{\circ} \mathrm{C}$. Next, $40 \mu \mathrm{L}$ of INT dye (2-p-iodophenyl-3-pnitrophenyl-5-phenyl tetrazolium chloride) (SigmaAldrich, St. Louis, MO, USA) at $0.125 \mathrm{mg} / \mathrm{mL}$ was added to each well and incubated for $1 \mathrm{~h}$ at $37^{\circ} \mathrm{C}$. Finally, the absorbance was detected using POLARstar Omega plate reader (BMG Labtech Pty. Ltd., Ortenberg, Germany), at a wavelength of $550 \mathrm{~nm}$. The lowest concentration of plant extract at which the color changed from yellow to pink was considered the MIC value.

\subsection{Minimum Bactericidal Concentration (MBC)}

Each bacterial species (0.5 McFarland standard) was diluted 1:100 in MH broth and incubated overnight at $37^{\circ} \mathrm{C}$ with shaking. A $10 \times$ dilution series $(2.5-20 \mathrm{mg} / \mathrm{mL})$ of each extract was made in $\mathrm{MH}$ broth. An amount of $90 \mu \mathrm{L}$ of the diluted bacterial suspension was individually added to each well. In addition, $10 \mu \mathrm{L}$ of the extracts was then added to each corresponding treatment well, while $10 \mu \mathrm{L}$ of $\mathrm{MH}$ broth was used as the positive control, and $10 \mu \mathrm{L}$ of the antibiotic $(10 \mathrm{mg} / \mathrm{mL})$ served as the antibiotic control to each corresponding bacterial strain. Plates were sealed and incubated overnight at $37^{\circ} \mathrm{C}$. Then, $2 \mu \mathrm{L}$ from each corresponding well was inoculated onto a fresh $\mathrm{MH}$ agar plate with a separate plate for each bacterial species. Plates were sealed and subsequently incubated overnight at $37^{\circ} \mathrm{C}$. The lowest concentration, where zero bacterial growth was observed, determined the MBC.

\subsection{Direct Enumeration Method for Biofilm Eradication}

Biofilm forming MRSA (ATCC 33591) was grown overnight at $37^{\circ} \mathrm{C}$ in nutrient broth media (Sigma-Aldrich, New South Wales, Australia) and then diluted 1:100 in fresh M63 minimal medium supplemented with magnesium sulphate (Sigma-Aldrich, New South Wales, Australia) and arginine (Sigma-Aldrich, New South Wales, Australia). An amount of $100 \mu \mathrm{L}$ of the diluted culture in M63 (Mg/Arg) was added to wells of the flat-bottomed 96-well microplate strips (Corning, Massachusetts, MA, USA; catalogue no: CORN9102), which was incubated for $48 \mathrm{~h}$ at $37^{\circ} \mathrm{C}$ under static aerobic conditions. After incubation, the spent supernatant containing planktonic cells were removed using a multichannel pipette (Nichipet EXII, Taufkirchen, Germany) and $90 \mu \mathrm{L}$ of M63 (Mg/Arg) was added to all wells. Then, $10 \mu \mathrm{L}$ of each $10 \mathrm{X}$ concentrated plant extract was added to achieve the desired final concentrations $(0.3-10 \mathrm{mg} / \mathrm{mL})$. An amount of $10 \mu \mathrm{L}$ of sterile water was added to the untreated control. The plate was incubated overnight at $37^{\circ} \mathrm{C}$. The contents from each preparation were aspirated and rinsed three times with $200 \mu \mathrm{L}$ of PBS (Astral 
Scientific, Taren Point, New South Wales, Australia). Each labeled well was separated from the microtiter plate and inserted to separate $8 \mathrm{~mL}$ sterile tubes containing $1.9 \mathrm{~mL}$ of PBS and capped after addition. The contents of each tube were sonicated for $8 \mathrm{~s}$ at $40 \%$ power. The resulting suspensions were inoculated on $\mathrm{MH}$ agar medium and viable cell counts were performed on the resulting bacterial colonies. It was assumed that the colonies formed from sessile bacteria that were trapped onto biofilms. Direct enumeration of colonies was performed using ImageJ software [36]. The following formula was used for the percentage inhibition calculation. Percentage Inhibition $=(\mathrm{CFU}$ in untreated sample-CFU in the treated sample)/CFU in the untreated sample $* 100$ (CFU: colony forming units).

\subsection{Antimicrobial Activity of S. hillii Methanol Extract Column Fractions}

Antimicrobial activity of the $S$. hillii methanol extract column fractions was determined using the WDA method. Based on the preliminary antimicrobial activity, five bacterial species including Gram-positive MRSA (ATCC 33591) and B. cereus (ATCC 14579), as well as Gram-negative P. vulgaris (ATCC 7002), A. baumannii (ATCC 19606), and E. cloacae (ATCC 13047), were selected to test the antimicrobial potential of 11 column fractions of $S$. hillii methanol extract at $50 \mathrm{mg} / \mathrm{mL}$. Column fractions were re-dissolved in milli-Q water (arium $^{\mathrm{TM}}$ pro, Sartorius, Germany), or 10\% isopropanol in milli-Q water depending upon the polarity of each fraction.

\subsection{Isolation of Bioactive Compounds from S. hillii Leaf Extracts}

Bioactive compounds were isolated and identified following specific and distinctive steps, including bioassay-guided fractionation and isolation of the compounds from the primary methanol extract of $S$. hillii. Primary fractions were eluted with a solvent gradient consisting of $600 \mathrm{~mL}$ volume fractions with $10 \%(\mathrm{v} / \mathrm{v})$ increments in each progressive step with dichloromethane (DCM) (Thermo Fisher Scientific, Scoresby, Victoria, Australia) and methanol using a glass column containing $50 \mathrm{~g}$ of silica gel (Merck, Darmstadt, Germany) $60 \AA$ conditioned with hexane. Testing for bioactivity was carried out at each primary fraction processing step. Active primary fractions collected from $S$. hillii methanol extracts were separated by preparative and analytical HPLC C18 columns. The mobile phase consisted of (A) $0.05 \% v / v$ formic acid in milli-Q water and (B) methanol. Compound structures were identified by ${ }^{1} \mathrm{H},{ }^{13} \mathrm{C}$, and 2D NMR spectra (COSY, HSQC, and HMBC) recorded at $600 \mathrm{MHz}$ on an Ascend ${ }^{\mathrm{TM}} 600$ spectrometer (Bruker, Thebarton, Australia). TopSpin $^{\mathrm{TM}} 4.0 .6$ software was used to analyze the NMR data. Finally, samples were analyzed on positive and negative ion modes with a range of $m / z 100-800$, at a scan rate of $0.5 \mathrm{~Hz}$ on a LTQ XLTM ion trap mass spectrometer (Thermo Scientific, Victoria, Australia) to determine and confirm the molecular weights of the structures.

\subsection{Antimicrobial Activity of the Isolated Compounds}

The antimicrobial activity and the MIC values of the isolated compounds were determined using the same semiquantitative method described in Section 4.4. Isolated compounds were initially dissolved in milli-Q water and diluted in MH broth. Four-fold dilution series consisting of final concentrations ranging between 0.78 and $200 \mu \mathrm{g} / \mathrm{mL}$ were tested against eight bacterial species, including Gram-positive, Gram-negative, and several ESKAPE pathogens.

\subsection{Statistical Analysis}

Statistical analyses were performed using GraphPad Prism 8.4.3 software. Triplicate samples were assayed in each technical experiment and replicated three times. The comparison among multiple groups was performed by two-way analysis of variance (ANOVA) followed by Dunnett's multiple comparisons test. The statistically significant levels were set at $p<0.05\left(^{*}\right), p<0.01\left(^{* *}\right), p<0.001\left(^{* * *}\right)$, and $p<0.0001\left(^{* * * *}\right)$. 


\section{Conclusions}

This is the first project to phytochemically investigate the pathological significance of S. hillii leaf extracts and cognate bioactive compounds. Overall, Staphylococcal species had the greatest susceptibility to methanolic extracts derived from the leaves of S. hillii as it produced the greatest antibacterial effects, including the impediment of biofilm formation. Two bioactive compounds were isolated and identified as quercetin-3-O- $\beta$-D-glucuronide and shikimic acid from the $S$. hillii methanol extract and demonstrated improved antibacterial effects against E. faecalis (QUT code 1105), P. vulgaris (ATCC 6380), E. cloacae (ATCC 13047), and $P$. aeruginosa (ATCC 27853). Consequently, this project has scientifically confirmed the potential antibacterial properties of $S$. hillii leaves, used traditionally to heal skin infections.

Supplementary Materials: The following are available online at https:/ / www.mdpi.com/article/10.3 390/plants11030283/s1, File 1: Spectroscopic data for quercetin-3-O- $\beta$-D-glucuronide and shikimic acid.

Author Contributions: Investigation, methodology, formal analysis, data analysis, writing —original draft preparation, M.M.N.P.; conceptualization, T.A.C. and M.M.N.P.; chemical structure elucidation, P.L.K. and S.N.D.; writing/editing, S.N.D. and T.A.C.; supervision, T.A.C., P.L.K. and S.N.D. All authors have read and agreed to the published version of the manuscript.

Funding: This research was funded by Salut Products Pty. Ltd. (formerly Health Focus Products Australia Pty. Ltd.), grant number 1400001143.

Institutional Review Board Statement: Not applicable.

Informed Consent Statement: Not applicable.

Data Availability Statement: The data presented in this study are available in Supplementary Materials.

Acknowledgments: This study was primarily conducted at KG-Q, QUT and supported by the Faculty of Health Research Scholarship and HDR student sponsorship. Some of the data reported here were acquired at the QUT Central Analytical Research Facility (CARF) operated by the Institute for Future Environments. Supplementary data edition by Lalehvash Moghaddam.

Conflicts of Interest: The authors declare no conflict of interest.

\section{References}

1. Attia, R.; Messaoud, C.; Arraki, K.; Zedet, A.; Demougeot, C.; Boussaïd, M.; Girard, C. Phytochemical screening and arginase inhibitory activity of extracts from several Tunisian medicinal plants. S. Afr. J. Bot. 2018, 120, 313-318. [CrossRef]

2. Cos, P.; Vlietinck, A.J.; Berghe, D.V.; Maes, L. Anti-infective potential of natural products: How to develop a stronger in vitro 'proof-of-concept'. J. Ethnopharmacol. 2006, 106, 290-302. [CrossRef] [PubMed]

3. Chaves, J.O.; de Souza, M.C.; da Silva, L.C.; Lachos-Perez, D.; Torres-Mayanga, P.C.; Machado, A.P.d.F.; Forster-Carneiro, T.; Vázquez-Espinosa, M.; González-de-Peredo, A.V.; Barbero, G.F.; et al. Extraction of Flavonoids From Natural Sources Using Modern Techniques. Front. Chem. 2020, 8, 507887. [CrossRef] [PubMed]

4. Oliver, S.J.J. The role of traditional medicine practice in primary health care within Aboriginal Australia: A review of the literature. J. Ethnobiol. Ethnomed. 2013, 9, 46. [CrossRef]

5. Akter, K.; Barnes, E.C.; Brophy, J.J.; Harrington, D.; Community Elders, Y.; Vemulpad, S.R.; Jamie, J.F. Phytochemical Profile and Antibacterial and Antioxidant Activities of Medicinal Plants Used by Aboriginal People of New South Wales, Australia. J. Evid.-Based Complementary Altern. Med. 2016, 2016, 14. [CrossRef]

6. Abe, R.; Ohtani, K. An ethnobotanical study of medicinal plants and traditional therapies on Batan Island, the Philippines. J. Ethnopharmacol. 2013, 145, 554-565. [CrossRef]

7. Brophy, J.J.; Craig, D.C.; Goldsack, R.J.; Fookes, C.J.R. Hilly acetate, a keto-acetate from the leaf steam volatiles of Syncarpia hillii. Phyfochenustry 1994, 37, 1645-1647.

8. Southwell, I.A.; Brophy, J. Essential Oil Isolates from the Australian Flora. Part 3. J. Essent. Oil Res. 2000, 12, 267-278. [CrossRef]

9. Brophy, J.J.; Goldsack, R.J.; Bean, A.R.; Forster, P.I.; Fookes, C.J.R. The Leaf Essential Oils of the Genus Syncarpia Ten. (Myrtaceae). Flavour Fragr. J. 1996, 11, 361-366. [CrossRef]

10. Setzer, M.C.; Schmidt, J.M.; Irvine, A.K.; Jackes, B.; Setzer, W. Biological activity of rainforest plant extracts from Far North Queensland, Australia. Aust. J. Med. Herbal. 2006, 18, 6-20.

11. Bayramov, D.; Li, Z.; Patel, E.; Izadjoo, M.; Kim, H.; Neff, J. A Novel Peptide-Based Antimicrobial Wound Treatment is Effective Against Biofilms of Multi-Drug Resistant Wound Pathogens. Mil. Med. 2018, 183, 481-486. [CrossRef]

12. Ayaz, M.; Junaid, M.; Ullah, F.; Sadiq, A.; Ovais, M.; Ahmad, W.; Ahmad, S.; Zeb, A. Chemical profiling, antimicrobial and insecticidal evaluations of Polygonum hydropiper L. BMC Complement. Altern. Med. 2016, 16, 502. [CrossRef] 
13. Ayaz, M.; Subhan, F.; Sadiq, A.; Ullah, F.; Ahmed, J.; Sewell, R.D.E. Cellular efflux transporters and the potential role of natural products in combating efflux mediated drug resistance. Front. Biosci. Landmark 2017, 22, 732-756. [CrossRef]

14. Sohn, U.-D.; Whang, W.-K.; Ham, I.-H.; Min, Y.-S.; Bae, K.-L.; Yim, S.-H.; Park, S.-Y. Process for Preparing Quercetin-3-O- $\beta$-DGlucuronide(qgc) Isolated from Rumex Aquaticus. WO/03/099307 A1, 4 December 2003.

15. Zeng, W.-C.; Zhang, Z.; Gao, H.; Jia, L.-R.; He, Q. Chemical Composition, Antioxidant, and Antimicrobial Activities of Essential Oil from Pine Needle (Cedrus deodara). J. Food Sci. 2012, 77, C824-C829. [CrossRef]

16. Frost, J.W.; Frost, K.M.; Knop, D.R. Biocatalytic Synthesis of Shikimc Acid; United States Patent and Trademark Office, Ed.; Board of Trustees operating Michigan State University: East Lansing, MI, USA, 2003.

17. Yang, L.; Wen, K.-S.; Ruan, X.; Zhao, Y.-X.; Wei, F.; Wang, Q. Response of Plant Secondary Metabolites to Environmental Factors. Molecules 2018, 23, 762. [CrossRef]

18. Steigbigel, R.T.; Steigbigel, N.H. Static vs Cidal Antibiotics. Clin. Infect. Dis. 2018, 68, 351-352. [CrossRef]

19. Friedel, J.K.; Mölter, K.; Fischer, W.R.J.B.; Soils, F.o. Comparison and improvement of methods for determining soil dehydrogenase activity by using triphenyltetrazolium chloride and iodonitrotetrazolium chloride. Biol. Fertil. Soils 1994, 18, 291-296. [CrossRef]

20. Alvarado-Gomez, E.; Perez-Diaz, M.; Valdez-Perez, D.; Ruiz-Garcia, J.; Magana-Aquino, M.; Martinez-Castanon, G.; MartinezGutierrez, F. Adhesion forces of biofilms developed in vitro from clinical strains of skin wounds. Mater. Sci. Eng. C Mater. Biol. Appl. 2018, 82, 336-344. [CrossRef]

21. Mihai, M.M.; Preda, M.; Lungu, I.; Gestal, M.C.; Popa, M.I.; Holban, A.M. Nanocoatings for Chronic Wound Repair-Modulation of Microbial Colonization and Biofilm Formation. Int. J. Mol. Sci. 2018, 19, 1179. [CrossRef]

22. Stathopoulou, M.K.; Banti, C.N.; Kourkoumelis, N.; Hatzidimitriou, A.G.; Kalampounias, A.G.; Hadjikakou, S.K. Silver complex of salicylic acid and its hydrogel-cream in wound healing chemotherapy. J. Inorg. Biochem. 2018, 181, 41-55. [CrossRef]

23. Shetty, B.S.; Udupa, S.L.; Udupa, A.L.; Somayaji, S.N. Effect of Centella asiatica L (Umbelliferae) on normal and dexamethasonesuppressed wound healing in Wistar Albino rats. Int. J. Low. Extrem. Wounds 2006, 5, 137-143. [CrossRef]

24. Pfalzgraff, A.; Brandenburg, K.; Weindl, G. Antimicrobial Peptides and Their Therapeutic Potential for Bacterial Skin Infections and Wounds. Front. Pharmacol. 2018, 9, 281. [CrossRef]

25. Li, H.-W.; Xiang, Y.-Z.; Zhang, M.; Jiang, Y.-H.; Zhang, Y.; Liu, Y.-Y.; Lin, L.-B.; Zhang, Q.-L. A novel bacteriocin from Lactobacillus salivarius against Staphylococcus aureus: Isolation, purification, identification, antibacterial and antibiofilm activity. LWT 2021, 140, 110826. [CrossRef]

26. Narayanan, K.B.; Park, G.T.; Han, S.S. Biocompatible, antibacterial, polymeric hydrogels active against multidrug-resistant Staphylococcus aureus strains for food packaging applications. Food Control 2021, 123, 107695. [CrossRef]

27. Jaśkiewicz, M.; Janczura, A.; Nowicka, J.; Kamysz, W. Methods Used for the Eradication of Staphylococcal Biofilms. Antibiotiocs 2019, 8, 174. [CrossRef]

28. Abdar, M.H.; Taheri-Kalani, M.; Taheri, K.; Emadi, B.; Hasanzadeh, A.; Sedighi, A.; Pirouzi, S.; Sedighi, M. Prevalence of extended-spectrum beta-lactamase genes in Acinetobacter baumannii strains isolated from nosocomial infections in Tehran, Iran. GMS Hyg Infect. Control 2019, 14, Doc02. [CrossRef]

29. Barrientos, S.; Stojadinovic, O.; Golinko, M.S.; Brem, H.; Tomic-Canic, M. Growth factors and cytokines in wound healing. Wound Repair Regen. 2008, 16, 585-601. [CrossRef]

30. da Costa Júnior, S.D.; de Oliveira Santos, J.V.; de Almeida Campos, L.A.; Pereira, M.A.; Magalhães, N.S.S.; Cavalcanti, I.M.F. Antibacterial and antibiofilm activities of quercetin against clinical isolates of Staphyloccocus aureus and Staphylococcus saprophyticus with resistance profile. Int. J. Environ. Agric. Biotechnol. 2018, 3, 266213. [CrossRef]

31. Amin, M.U.; Khurram, M.; Khattak, B.; Khan, J. Antibiotic additive and synergistic action of rutin, morin and quercetin against methicillin resistant Staphylococcus aureus. BMC complementary Altern. Med. 2015, 15, 59. [CrossRef]

32. Bai, J.; Wu, Y.; Liu, X.; Zhong, K.; Huang, Y.; Gao, H. Antibacterial Activity of Shikimic Acid from Pine Needles of Cedrus deodara against Staphylococcus aureus through Damage to Cell Membrane. Int. J. Mol. Sci. 2015, 16, 27145-27155. [CrossRef]

33. Higuita, N.I.A.; Huycke, M.M. Enterococcal Disease, Epidemiology, and Implications for Treatment. In Enterococci: From Commensals to Leading Causes of Drug Resistant Infection; Gilmore, M.S., Clewell, D.B., Ike, Y., Shankar, N., Eds.; Massachusetts Eye and Ear Infirmary: Boston, MA, USA, 2014.

34. Anderson, A.C.; Jonas, D.; Huber, I.; Karygianni, L.; Wölber, J.; Hellwig, E.; Arweiler, N.; Vach, K.; Wittmer, A.; Al-Ahmad, A. Enterococcus faecalis from Food, Clinical Specimens, and Oral Sites: Prevalence of Virulence Factors in Association with Biofilm Formation. Front Microbiol. 2016, 6, 1534. [CrossRef] [PubMed]

35. Esmail, M.A.M.; Abdulghany, H.M.; Khairy, R.M. Prevalence of Multidrug-Resistant Enterococcus faecalis in Hospital-Acquired Surgical Wound Infections and Bacteremia: Concomitant Analysis of Antimicrobial Resistance Genes. Infect. Dis. Res. Treat. 2019, 12, 1178633719882929. [CrossRef] [PubMed]

36. Merritt, J.H.; Kadouri, D.E.; O’Toole, G.A. Growing and analyzing static biofilms. Curr. Protoc. Microbiol. 2005, 1, 1B.1.1-1B.1.18. [CrossRef] 